\title{
ORGULLO CULTURAL Y AMBIVALENCIA: ACTITUDES ANTE LA LENGUA ORIGINARIA EN LA SOCIEDAD MAPUCHE CONTEMPORÁNEA*
}

\section{CULTURAL PRIDE AND AMBIVALENCE: ATTITUDES ABOUT NATIVE LANGUAGE IN CONTEMPORARY MAPUCHE SOCIETY}

\section{HANS GUNDERMANN K.}

Universidad Católica del Norte. San Pedro de Atacama, Chile

hgunder@ucn.cl

\section{RESUMEN}

Las percepciones y actitudes lingüísticas mapuches actuales pueden entenderse en el contexto de la dominación y minorización del mapuzugun. Así ocurre con la pérdida progresiva de vitalidad lingüística de la lengua vernácula en la gran mayoría de sus indicadores objetivos (número de hablantes, niveles de competencia, funciones, ámbitos de uso, etc.). Al mismo tiempo, el dinámico activismo cultural constatable entre los mapuches tiene repercusiones positivas para la reconsideración del valor de la lengua y la cultura. Refuerza las percepciones positivas, aunque subordinadas, que desde hace mucho mantenían acerca de la cultura propia y de una de sus instituciones centrales, el mapuzugun. Ellas contribuyen a generar una nueva imagen de la lengua, cambiando la extendida percepción que la hacía un idioma asociado con los orígenes rurales, exclusivo de los ámbitos sociales que son particulares a los mapuches. Pero el aumento del orgullo cultural y del prestigio lingüístico se enfrentan con una vitalidad lingüística en declinación, por lo que la lealtad lingüística tiende, paradojalmente, a hacerse más discursiva.

Palabras clave: Mapuzugun, mapuches de Chile, minorización, actitudes lingüísticas, ideología lingüística.

\section{ABSTRACT}

Mapuche's linguistic perceptions, attitudes and practices can only be understood in the context of minorization of mapuzugun, as it occurs with the progressive loss of linguistic vitality of the native language, who affects the great majority of its objective indicators

\footnotetext{
* Trabajo realizado en el Proyecto Fondecyt Nº1110246.
} 
(speakers, competence levels, functions, use realms, etc.). At the same time, the dynamic cultural activism we observe by the Mapuche today has some positive impact on the reconsideration of language's and culture's value, reinforcing favorable perceptions about own culture and one of its main institutions: the language. These perceptions existed from long ago but occupied a secondary place. They contribute to generate a new image of their language, changing the extended conception that associated it exclusively to its rural origins and Mapuche social spaces. At the same time, the strengthening of cultural pride and linguistic prestige coexists with a declinant linguistic vitality, so, linguistic loyalty tends to become discursive than practical.

Keywords: Mapuzugun, Chilean Mapuche, minorization, linguistic attitudes, linguistic ideology.

Recibido: 14/12/2012. Aceptado: 29/05/2013.

\section{INTRODUCCIÓN ${ }^{1}$}

Dara cualquier observador externo, es notoria la fuerza con que hoy los mapuches asumen abiertamente su pertenencia étnica e identificación con la tradición cultural en los más diversos ámbitos y relaciones, tanto de parte de hombres como de mujeres, de viejos y jóvenes, de habitantes rurales y urbanos. Todo ello contrasta con la autonegación o invisibilización cultural que tendió a predominar durante el siglo XX, pese a que hubo siempre organizaciones políticas que buscaron combatir este proceso y mantener vigentes los elementos culturales considerados propios como la organización social, la religión y la lengua ${ }^{2}$.

La cultura, la sabiduría ancestral, las prácticas médicas, la sabiduría acerca de

${ }^{1}$ Agradezco el interés y dedicación de dos lectores anónimos de este trabajo, quienes efectuaron una revisión detallada y varias observaciones y críticas que han orientado los cambios que se presentan en la presente versión. Algunos de esos alcances rebasan toda posibilidad de ser abordados y discutidos suficientemente aquí, no obstante la importancia que puedan tener. Pero señalan la necesidad de profundizar la investigación de diversos tópicos socio o etnolingüísticos en el área de los estudios étnicos en Chile. Los propósitos de este trabajo son específicos y se abocan a analizar solo algunas dimensiones, que consideramos relevantes, del campo de las ideologías, las actitudes y prácticas lingüísticas mapuches de hoy. Tenemos el anhelo que la información e ideas aquí elaboradas tengan interés para los especialistas y ayuden a formular nuevas y más incisivas preguntas de investigación en estas materias.

${ }^{2}$ Fue el caso de la Sociedad Caupolicán y de la Federación Araucana, en especial esta última, formadas a principios del siglo, en 1938, luego refundidas en la Corporación Araucana, que se transformó en la principal organización política mapuche hasta inicios de la década de 1960. Por el contrario, la Unión Araucana, nacida al alero de los Capuchinos Bávaros, propició el abandono de la lengua y de las tradiciones culturales mapuches tenidas por "bárbaras" a la luz del catolicismo, como la poligamia. Al respecto, el estudio más completo sigue siendo el de Foerster y Montecino (1988). Hay trabajos más recientes que profundizan respecto de organizaciones, líderes y períodos específicos. 
la naturaleza, las representaciones cosmológicas y religiosas, la lengua propia o las prácticas rituales han sido revalorizadas y puestas en posición de igualdad y, en muchos casos, de superioridad respecto de la cultura y la lengua nacionales dominantes. En todo esto hay en juego una dignidad y un orgullo como pueblo que afirma su propia cultura y los defiende ante algún cuestionamiento o puesta en entredicho.

El cambio es atribuible a dos procesos relacionados. Por un lado, a la puesta en marcha de una política pública de reconocimiento étnico en que lo cultural y lo lingüístico ocupan un lugar secundario, pero no irrelevante. Por otra parte, debe agradecerse al desarrollo de una activa elite de intelectuales mapuches y agentes indígenas de lo cultural ${ }^{3}$. Tanto los intelectuales como los agentes culturales aprovechan los recursos y canales de manifestación y promoción cultural abiertos por la política pública indígena y sus instituciones, ya sea específicas (CONADI), que implementan programas (MINEDUC, MINSAL) o que consideran cursos de acción indígena (en los municipios, más notoriamente). Como fruto de estas políticas, se editan libros y material escolar, bilingüe o con pertinencia cultural; se organizan festivales culturales, exposiciones, presentaciones artísticas y se forman registros de memoria histórica, recuperación de tradiciones e instituciones culturales. Por otro lado, los ámbitos de acción en esta materia desbordan las posibilidades abiertas por el Estado y de manera autónoma se despliegan globalmente (sitios y páginas de Internet), en el espacio nacional-regional (Internet, periódicos, programas radiales) y en el local externo (ferias de artesanía y grupos de acción cultural local, por ejemplo) e interno (ciclos rituales, acción de especialistas médicos).

Todo esto contrasta con lo que ocurría hasta hace un par de décadas en que no existía contrapeso, salvo testimonial, al hecho de que la cultura y lengua mapuche fueran ignoradas y hasta despreciadas por la población del país, particularmente en las regiones del sur de Chile. Y si se las consideró dignas de atención (por ejemplo, en la educación nacional, por parte de intelectuales, en círculos literarios o políticos), lo fue por constituir un elemento o parte de la construcción nacional (folklore), al mismo tiempo que como algo del pasado (su historia de rebeldía), que no se condecía con la postración social que sus integrantes manifestaban en el presente; o, en otra versión, como un segmento de clase explotada respecto del cual correspondía romper las cadenas de la explotación, pero poco o nada su emancipación cultural y lingüística ${ }^{4}$. La propia población mapuche tendió a

${ }^{3}$ De los primeros: líderes, profesionales, sabios, profesores, dirigentes; y entre los segundos: cultores, educadores, practicantes de medicina, artesanos, autoridades culturales, artistas, agrupaciones y organizaciones de la cultura, grupos de música, danza y teatro, agentes de la política cultural indígena. En relación con los intelectuales indígenas, especialmente mapuches, en Chile la principal investigadora del tema es Claudia Zapata (Zapata, 2005, 2006 y 2008). No ha habido un igual interés por el tema de los agentes culturales, pero una tesis de maestría en EIB en el PROEIB Andes entrega una buena aproximación (Ancapi, 2006).

${ }^{4}$ Aunque hubo excepciones. En febrero de 1927, Carlos Contreras Labarca, diputado del Par- 
incorporar las premisas del desprestigio cultural y los efectos de la dominación y minorización lingüística, como intentaremos poner de manifiesto más abajo. Las huellas y consecuencias de todo eso todavía están presentes.

La relación interna, de los mapuches con su cultura y lengua, está entonces cambiando rápidamente (una presentación inicial sobre este tema en Gundermann, 2013), del mismo modo como, aunque parcial y paulatinamente, lo está haciendo externamente. En ambos casos, con barreras, dosis de ambigüedad y contradicciones. En efecto, se abre paso lentamente una sensibilidad positiva hacia las prácticas culturales indígenas (en el mercado de la moda y el turismo por ejemplo) y en la propia sociedad chilena ${ }^{5}$. Pero ello no garantiza que esa legitimidad que se anuncia tenga vigencia en toda la sociedad chilena o siquiera en la mayoría de ella y que no tenga grandes fisuras. Junto con cambios de esa mirada perviven viejos estereotipos (en Araucanía, la del mapuche que hace poco por superarse a sí mismo) y se construyen nuevos prejuicios (como el del mapuche $=$ conflicto $=$ violencia, o el de favorecido por y dependiente del Estado) ${ }^{6}$.

tido Comunista -y quien sería, pocos años después, también su secretario general- realizó una vehemente defensa de los mapuches contra el proyecto de ley de división de las comunidades. Si bien recalcó que "dichas comunidades no representan la realización del comunismo" al que aspiraba su partido, agregó: "Defendemos, sin embargo, el régimen de los indios, porque nosotros respetamos las costumbres de esta minoría nacional y respetamos igualmente el idioma y la idiosincrasia particular de la raza, pero aspiramos naturalmente a perfeccionarla y la ayudaremos a superar sus propias deficiencias" (Sesiones Cámara de Diputados, 1927). En 1932, la Federación Obrera de Chile convocó al XI Congreso Araucano, entre cuyas conclusiones estuvo el derecho de los mapuches a "hablar su propio idioma". Dos años después, a propósito del levantamiento de Ranquil, donde participaron trabajadores, colonos y mapuches, comenzó a hablarse de la "República Araucana", reconociéndose a ésta, en alianza con obreros y campesinos, el derecho a mantener sus costumbres e idioma (cit. por Téllez, 2001). Pero será recién Alexander Lipschutz, el sabio letón radicado en Chile a fines de la década de 1920 y también de militancia comunista, quien -paralelamente a la Corporación Araucana- llegará a desarrollar una concepción sistemática de defensa de la cultura indígena y, dentro de ella, de la lengua. En un notable artículo fechado en 1953, Lipschutz subraya, por un lado, la vigencia de las lenguas indígenas frente a quienes hablan de su cuasi-desaparición; contradice asimismo la afirmación de que su uso supone un obstáculo para aprender el español y plantea, por último, que ha habido un cambio en el concepto de nación que significa dejar atrás el monolingüismo como ideal: "debemos tener presente el hecho de que la moderna idea de nación polilingüe es muy distinta de cierta idea de la nación de siglos pasados - de la nación política de los Incas, por ejemplo, o de la nación politica del siglo XIX; es decir, cuando el 'ideal' de la nación era el estado monolingüe" (Lipschutz, 1968: 102).

${ }^{5}$ Confróntese, Encuesta CERC de 1999, citada por Lavanchy, 2003; también algunos de los resultados de la encuesta sobre relaciones interétnicas mapuche y aymara del Programa de las Naciones Unidas para el Desarrollo: Pueblos originarios y sociedad nacional en Chile. La interculturalidad en las prácticas sociales. Programa de las Naciones Unidas para el Desarrollo (PNUD), Santiago de Chile, 2013.

${ }^{6}$ Por lo demás, se recordará que en los pueblos indígenas del país el pentecostalismo religioso se encuentra bastante extendido, y esas iglesias son por lo general opositoras a las prácticas tradicionales que consideran paganas; o, también, el numeroso contingente de personas que en medios urbanos han optado por una integración social y cultural a la sociedad nacional sin identificarse con sus antecedentes culturales y lingüísticos mapuches. $\mathrm{O}$, si esto no es así, evidenciando grandes brechas en las prácticas culturales y lingüísticas efectivamente ejercidas. 
El activismo cultural y la apertura lingüística que está teniendo lugar tendrían efectos importantes en la reproducción de la identidad-alteridad étnica mapuche. Lo es en la medida que una cultura e idioma revalorados y puestos en el sitial de símbolos colectivos centrales y políticamente estratégicos definen, junto con la tierra y la memoria de su despojo, mucho del contenido y los límites de la identidad étnica mapuche contemporánea. Pero es posible que sus consecuencias sean bastante más limitadas, ambiguas en ciertos aspectos y no exentas de paradojas, en el ámbito de las lealtades culturales y lingüísticas. Ello sería atribuible a la persistencia de nociones y creencias relativas a la lengua vernacular que, revalorada y todo, se la sigue pensando básicamente como un idioma de las relaciones internas allí donde todavía se dispone de ella, en un contexto de intensa integración de las áreas rurales tradicionales a sus regiones, los mercados de trabajo, la vida urbana e instituciones como la escuela pública nacional. Dada esa integración, se participa de dominios diversos de monolingüismo castellano exclusivo y excluyente. Se pretende allegar elementos de juicio a estas aseveraciones. Las ideologías lingüísticas ${ }^{7}$ y, formando parte de ellas, las actitudes y prácticas lingüísticas representan una dimensión relevante para abordar la diferencia que se propone entre una identidad étnica que se expande y una subjetividad hacia lengua y cultura cruzada por diferencias, ambigüedades y paradojas. Ideologías y patrones de uso de la lengua son temas poco conocidos respecto de los cuales los estudios existentes empiezan a poner de relieve algunos de sus aspectos ${ }^{8}$. Con limitaciones y en relación con el tema que se abordará, la documentación existente en la materia y la experiencia ganada permiten apoyar la plausibilidad de la interpretación que se avanza.

Las actitudes lingüísticas, percepciones, valoraciones, juicios, creencias, evaluaciones, justificaciones, doxas, elementos de sentido común respecto del mapuzugun y castellano en el contexto de vida social mapuche que aquí ponemos en evidencia cabe considerarlos bajo el concepto de ideologías lingüísticas. La noción de ideología lingüística no tiene una acepción unívoca. Resulta útil lo señalado por Woolard, citando a otros autores y especificando aspectos de su interés: "Linguistic ideologies are 'shared bodies of commonsense notions about the nature of language in the world' (Rumsey, 1990: 346). We mean to include cultural conceptions not only of language and language variation, but of the nature and purpose of communication, and of communicative behavior as an enactment of a collective order (Silverstein, 1987: 1-2)" (Woolard, 1992:235; Woolard, 1998: 3-47).

${ }^{8}$ El autor se ha basado en la literatura que estuvo a su alcance acerca de las actitudes, las prácticas lingüísticas y en el conocimiento práctico resultante de múltiples interacciones y diálogos con personas mapuches rurales y urbanas a lo largo de muchos años. Las publicaciones e informes que abordan las disposiciones subjetivas mapuche acerca de su lengua y cultura son pocas y dispersas. Es un campo de investigación, entre otros, que requiere mucha más investigación y discusión, posiblemente interdisciplinaria. De algunos estudios recientes el autor ha sido partícipe junto a otros profesionales. 


\section{PERCEPCIONES, ACTITUDES Y ALGUNAS PRÁCTICAS MAPUCHES CON EL MAPUZUGUN}

\subsection{Actitudes ante la lengua mapuche en el sur de Chile (2007) ${ }^{9}$}

\section{Un test de actitudes ${ }^{10}$ aplicado a integrantes de un par de miles de hogares mapu- ches (exactamente 2.006 casos) del sur de Chile ${ }^{11}$ entregó algunos resultados de interés para los propósitos de este artículo, que se resume a continuación ${ }^{12}$. Las di-}

${ }^{9}$ Este estudio y el que se resume a continuación se basaron en encuestas (hogares y test a personas) y, complementariamente, en entrevistas cualitativas. Las encuestas fueron diseñadas para describir cuantitativamente dimensiones sociolingüísticas de interés para la Corporación Nacional de Desarrollo Indígena (CONADI), la institución mandante. No se consideró la aplicación de modelos estadísticos multivariados (como correlaciones o regresiones). En la presentación que hacemos nos basamos, entonces, en los resultados contenidos en los informes entregados a la institución pública mandante; no disponiendo para efectos de nuevos análisis de las bases de datos correspondientes. Con la salvedad de algunas técnicas de observación participante no nos es dado contar con ambientes "naturalísticos" de investigación. La gran mayoría son en un grado mayor o menor artificiales (afectados de una u otra manera por los investigadores, su intervención en los ambientes sociales que tocan y los instrumentos de indagación que aplican). Los estudios en que sustentamos los análisis vertidos en este artículo no escapan a esta condición. Con razón preocupa a uno de los comentaristas de este trabajo el efecto de la presencia de los investigadores y del instrumento en las respuestas y los resultados alcanzados. Es oportuno señalar que los estudios en que nos apoyamos se realizaron en castellano y en lengua mapuche por hablantes competentes en la lengua vernácula, a una comunidad lingüística mapuche en parte monolingüe del castellano (la mayoría) y en parte bilingüe (la minoría). Aunque existe la posibilidad que "la negociación activa de los contenidos de las preguntas disparan los resultados o lo hace el interés-presencia de los investigadores", y ese efecto pueda estar presente, los controles de campo (generación de ambientes de confianza, revisitas, entrevistas de control), la triangulación de técnicas e instrumentos (encuesta a hogares, test de competencia interhablantes, test de actitudes, entrevistas a personalidades locales, observaciones de campo durante el periodo de investigación, reuniones de análisis de la actividad de campo), la triangulación de métodos (encuesta, test, entrevistas cualitativas, observación) y la triangulación de resultados (buscando establecer su convergencia y dilucidando diferencias), permiten afirmar la plausibilidad de las inferencias realizadas. Estudios diseñados para abordar los temas tratados sobre bases metodológicas y técnicas más específicas o especializadas, en su conjunto o en particular, permitirán mejorar lo obtenido, profundizarlo, corregirlo y también confirmarlo si es el caso.

${ }^{10}$ Se entiende por actitud lingüística, en sentido amplio, las disposiciones subjetivas relativas a una lengua, una variedad o una situación de bi o multilingüismos, presentes en los individuos integrantes de una comunidad o colectividad dada. Se intersecta o relaciona con fenómenos cercanos tales como representación, evaluación, estereotipo, juicio u opinión lingüísticas. Suele reconocerse en una actitud lingüística dimensiones cognitivas (conocimientos, visiones, juicios), afectivas (sentimientos de muy diverso tipo, signo y fuerza) y conativas (referidas al comportamiento y la acción socialmente situada). Además de su interés intrínseco, el conocimiento de las actitudes resulta importante porque mantienen un nexo, de alcance variable, con los comportamientos y usos que las personas realizan respecto de una lengua o relación lingüística (congruencia, lealtad, o la ausencia de esto, por ejemplo). Un buen resumen sobre este concepto tal como ha sido aplicado en la sociolingüística se encuentra en Fasold, 1996: 229-274.

${ }^{11}$ Perfil sociolingüístico de comunidades mapuche de la VIII, IX y X Región, CONADI UTEM, 2007 (Cf. Gundermann, Caniguan, Clavería y Faúndez, 2008).

${ }^{12}$ Los estudios que abordan las actitudes lingüísticas hacia el mapuzugun ponen en evidencia varios elementos subjetivos de interés. Se ha creído pertinente concentrar la atención en uno de ellos, 
mensiones temáticas cubiertas fueron tres. Primero, la legitimidad de la lengua, la creencia en su valor, su centralidad cultural, su importancia para la etnia y el país, que puede ser tanto interna ( situada en contextos intraétnicos) como externa. Segundo, los nexos entre lengua originaria y vida social mapuche (tanto la tradicional como la modernizada, la que se vive en los centros urbanos). Finalmente, la reproducción de la lengua (su continuidad) y su opuesto (el desplazamiento por el castellano) ${ }^{13}$.

El mapuzugun goza en la conciencia general mapuche de una muy alta legitimidad interna; esto es, que su lengua posee un valor cultural y potencial lingüístico como el de la lengua oficial y dominante ${ }^{14}$. Una misma aprobación, igualmente alta, se traslada a contextos sociales interétnicos, como el de la relación con autoridades $^{15}$. Lo que resalta aquí es el reconocimiento que resulta de su empleo por personas no mapuches o mapuches en posiciones de poder. No obstante gozar de una aprobación mayoritaria (un 70,5\% de los casos), se tiene más dudas acerca de lo que la lengua propia tiene que aportar a los "chilenos" o no mapuches, lo que parecería indicar que en bastante mayor grado se da legitimidad interna a la lengua (en la comunidad indígena o en ámbitos de interacción social donde ellos se hacen presente) y que ello no se traslada con tanto ascendiente más allá de esos límites $^{16}$. De allí entonces que la afirmación acerca de la utilidad de que los mapuches aprendan a escribir en mapuzugun, con un muy alto acuerdo (un 95,4\%), deba interpretarse por el prestigio acordado al desarrollo de la escritura y la literacidad de una lengua, más que como un recurso de uso general aplicable efectivamente para desempeñarse en la sociedad de hoy.

Al remitirse ahora a la relación entre lengua y vida social y cultural mapuche,

que resalta notoriamente: el de la ambivalencia en la lealtad hacia la lengua mapuche. Otros varios no podemos considerarlos sino parcialmente, o apenas mencionarlos, a pesar de su muy evidente interés. Por ejemplo, la revitalización de la lengua vista crecientemente como algo que cabe en el ámbito de las responsabilidades de las instituciones de educación formal nacional, la posición pasiva en las prácticas de transmisión de la lengua, el purismo lingüístico, la percepción de disfuncionalidad de la lengua para enfrentar la vida social moderna o el anhelo de literacidad.

${ }^{13}$ El test constó de 23 aseveraciones cognitivas (afirmaciones que enuncian juicios, ideas, razonamiento sobre la lengua vernácula, el castellano y el bilingüismo), afectivas (aquellas que reflejan sentimientos, la repercusión emocional asociada a la lengua, adhesiones e identificaciones emocionales, rechazos y sentimientos de malestar) y conativas (aquellas que se traducen en disposiciones a la acción frente a la lengua, en cualquier sentido que ello se oriente). Las aseveraciones se formulan de manera afirmativa o negativa y respecto de cada una de ellas se pidió a los entrevistados tomar posición en una escala nominal que va desde el máximo acuerdo hasta el máximo desacuerdo.

${ }^{14}$ Un 93,2\% de acuerdo logró la proposición: "El mapuzugun es tan importante como el castellano".

${ }^{15}$ Se planteó que algo muy deseable y gratificante resultaría del hecho que funcionarios públicos y autoridades mapuches y no mapuches conocieran y hablaran la lengua indígena. En sendas aseveraciones se alcanzan valores de aprobación de un 96,2 y 90,5\%.

${ }^{16} \mathrm{El}$ aserto fue "Los chilenos no tienen nada que aprender del mapuzugun" y en acuerdo con ello o con indiferencia se pronunció un $29,5 \%$ de los casos. 
se establece un vínculo directo entre relato y comunicación de lo propio, como es el caso de la historia mapuche, y el mapuzugun ${ }^{17}$. Pero, este nexo es percibido con algo menos fuerza para la relación entre costumbre -la cultura y las prácticas mapuches, el ad mapu- y lengua, respecto de la que un 22,0\% de los encuestados se manifestó en desacuerdo con que la costumbre no podría mantenerse sin la lengua propia. Para la mayoría de los mapuches vivir y practicar la costumbre con la lengua no es una alternativa posible. Ahora, en claro contraste con lo anterior, respecto de la relación entre lengua vernácula y vida social mapuche "moderna" (en las experiencias de vida y trabajo contemporáneas, normalmente fuera de los espacios locales mapuches históricos) se tiene bastante más dudas acerca de la funcionalidad de la lengua. Así, por ejemplo, la utilidad del mapuzugun para comunicarse en la "vida moderna" tiene un 39,9\% de desacuerdo en que ello sea efectivo $^{18}$. Y, cuando se está dispuesto a suscribir lo contrario, plausiblemente se está dando una respuesta de afirmación expresiva (sustentada en sentimientos de identificación y pertenencia) y no una efectiva creencia en la funcionalidad de la lengua más allá de los espacios sociales intraétnicos.

Finalmente, referido a la continuidad o el desplazamiento de la lengua seguimos encontrando un decidido apoyo por su permanencia ${ }^{19}$. Adhesión que se traslada, al menos declarativamente, a una posición activa respecto de su mantenimiento y desarrollo ${ }^{20}$. Sin embargo, a la hora de posicionarse respecto de las condiciones, los instrumentos y los agentes que deben estar presentes para generar un cambio de dirección en la dinámica de permanencia de la lengua se nos presentan distribuciones bastante más matizadas. Por ejemplo, un 49,3\% suscribe la idea de que la enseñanza del mapuzugun debe ser preferentemente realizada por los mayores (los "abuelos"), en circunstancias que es una tarea que compete a todos. Lo que frecuentemente se acompaña con un imperativo de purismo ${ }^{21}$, que poco ayuda a una lengua respecto de la cual todos advierten su estado de franco retroceso $^{22}$. Si se amplia la perspectiva de análisis y se sale de lo que puede acordarse en

${ }^{17}$ La aseveración fue: "El mapuzugun es importante para transmitir nuestra historia” y ella tuvo un $96,0 \%$ de aprobación.

${ }^{18}$ Otras frases en el mismo sentido fueron: "Los niños no necesitan aprender mapuzugun para surgir en la vida" con un 33,9\% de aprobación y "me da pena, pero es cierto que el idioma mapuche no le sirve a la gente indígena para mejorara su vida" con un 36,7\% de aprobación.

19 Ante una proposición como: "Me daría pena que el mapuzugun se perdiera” un 92,6\% se pronuncia afirmativamente. O también, un 93,3\% de aprobación para la proposición: "Me gustaría que toda la familia hablara mapuzugun"; o un 89,5\% para: "Es triste que los padres no hablen mapuzugun con sus niños".

${ }_{20}$ Por ejemplo, un 97,4\% apoya la aseveración: "Los mapuches tenemos que preocuparnos más por mantener el mapuzugun", y un 81, 4\% lo hace con: "Estoy dispuesto(a) a dedicar parte de mi tiempo para aprender (más) mapuzugun".

${ }^{21}$ Para la afirmación: "Hay que saber hablar bien mapuzugun para hablarlo" un 81,2\% se pronunció positivamente.

${ }^{22}$ La posición relativamente favorable hacia el purismo lingüístico que se manifiesta en las respuestas a la disyuntiva entre hablar la lengua mapuche cuando se posee un elevado nivel de compe- 
llamar condiciones de reproducción interna de la lengua, para dirigirse a aquellas externas, se pone de manifiesto la tendencia a desplazar la función de transmisión, internamente a los mayores y ancianos, como ya vimos, y externamente a algunas agencias estatales. Una aseveración pide pronunciarse por los mapuche o el Estado como el principal agente de la continuidad y desarrollo del mapuzugun y respecto de ella un 43,6\% optó por atribuir esa responsabilidad a la propia sociedad indígena, pero al mismo tiempo un 41,2\% se inclinó por aprobar la idea de que en el "gobierno" está radicada la mayor responsabilidad en mantener y aumentar el mapuzugun ${ }^{23}$. Para fines prácticos, en las instituciones educativas, las que deberían actuar premunidas de un mandato de obligatoriedad ${ }^{24}$.

\subsection{Actitudes lingüísticas en la Región Metropolitana según encuesta (2008)}

En un estudio sociolingüístico realizado durante 2008 en Santiago con población mapuche y aymara ${ }^{25}$ se aplicó un test de actitudes a 845 personas mapuches, integrantes de otros tantos hogares indígenas metropolitanos entrevistados. El test, con pequeños cambios, es el mismo que se aplicó en el centro-sur de Chile en el estudio sociolingüístico basado en encuestas que allí se realizara en 2007 y cuyos resultados principales se resumieron en el punto 2.1. En esta investigación se arriba a conclusiones convergentes con ese estudio previo, aunque con particularidades que son propias a la realidad urbana estudiada. Al igual que en el caso anterior, los temas abordados por el test fueron tres: legitimidad interna o externa de la lengua; la vinculación entre lengua originaria y vida social mapuche tradicional y

tencia, o practicarlo bajo cualquier condición de conocimiento, guarda relación con la presencia y, en cualquier caso, la memoria, de tipos discursivos del mapuzugun (Carrasco, 2002). La diferenciación entre la comunicación cotidiana y formas discursivas formales de alto prestigio como el weupin, nütram, ül, epeu, koneu, pentukun, etc. supone para el desarrollo de estas últimas un adecuado dominio de la lengua. Esa competencia verbal, un ideal lingüístico y cultural, ayuda a entender la notoriedad de una demanda de purismo para el empleo de la lengua. Este ideal cultural suele estar más notoriamente presente entre intelectuales, sabios y agentes culturales con competencias desarrolladas en su lengua. Ahora bien, dada la prevalencia de bilingüismos recesivos del mapuzugun respecto del castellano, la defensa del purismo lingüístico puede representar un obstáculo cultural para las acciones de revitalización. Constituye por sí mismo una materia digna de indagación, análisis detallado y discusión de sus implicaciones prácticas para la enseñanza y la revitalización de la lengua. Escapa a las posibilidades de este artículo tratarlo más extensamente.

${ }^{23}$ La proposición fue: "Mantener y aumentar el mapuzugun es una tarea del gobierno más que de los mapuche".

${ }^{24}$ Se pidió pronunciarse acerca de si "La enseñanza del mapuzugun debería ser obligatoria para los niños", frase que remite principalmente a la acción de instituciones educativas, las de la enseñanza formal en primer lugar.

${ }^{25}$ Perfil sociolingüístico de lenguas mapuche y aymara en la Región Metropolitana, CONADI - UTEM, 2008 (cf. Gundermann, Godoy, Caniguan, Ticona, Castillo, Clavería y Faúndez, 2009). 
moderna y la persistencia o el desplazamiento de la lengua vernácula ${ }^{26}$.

Respecto del primer tema general, la lengua originaria mantiene entre los mapuches de Santiago un elevado valor si se le juzga a partir de la importancia relativa que se le dio. En efecto, un 93,5\% de los encuestados estuvo de acuerdo en la relevancia intrínseca del mapuzugun respecto del castellano. Importancia que todavía se mantiene si se considera el valor de su empleo por autoridades y funcionarios mapuches y no mapuches, entendiendo que se trata de actos de lealtad lingüístico-cultural, en un caso, y reconocimiento, en el otro. Constituyen, por lo tanto, expresiones de legitimidad tanto interna como externa ${ }^{27}$. Con todo y lo anterior, aunque el aprendizaje de la lengua de manera escrita y su eventual utilidad goza de una altísima aceptación (96,4\%), ello mismo puede entenderse también como el anhelo de poseer una lengua más "completa" (en términos de sus usos modernos) y funcional.

Relativo al vínculo entre mapuzugun y vida social mapuche existe un nexo estrecho entre la lengua y la transmisión de la historia, la cultura propia y la continuidad del admapu (la costumbre mapuche) ${ }^{28}$. Se trata, por cierto, de una relación más deseada que realizable, habida cuenta de las disminuidas capacidades con que es posible en la mayoría de los hogares mapuches metropolitanos llevar a efecto lo anterior. En una dirección inversa se presentan los resultados obtenidos con proposiciones que conectan lengua mapuche y vida "moderna" (urbana, en interacción cotidiana con no mapuches), sus posibilidades y utilidad. En efecto, ante la aseveración acerca de la utilidad del mapuzugun para comunicarse en la vida moderna, un 46,6\% se manifestó en desacuerdo; esto es, que no apreciaban que la lengua pudiera emplearse provechosamente en las circunstancias de vida actual (se entiende: urbanas, fuera del hogar). De todos modos, el anhelo porque esto cambie también está presente ${ }^{29}$.

En cuanto a la relación entre lengua y la disyuntiva permanencia/desplazamiento, la opción por la continuidad y desarrollo de la lengua tomada en general no tiene dos lecturas. Un visible rechazo tiene la posibilidad que la lengua propia pueda llegar a desaparecer (un 96,2\%). Al mismo tiempo, se manifiesta satisfacción porque el dominio de la lengua sea extensible a toda la familia (un 91,1\%)

${ }^{26}$ Las 23 proposiciones consideradas se frasearon negativa o positivamente y para cada una de ellas se pidió pronunciarse entre tres alternativas: de acuerdo, indiferente o en desacuerdo.

${ }^{27} \mathrm{La}$ consulta por la satisfacción de que las autoridades y funcionarios públicos mapuches empleen el mapuzugun alcanzó un 89,1\% de aprobación y el del aprendizaje y empleo por funcionarios y autoridades no mapuches un $82,3 \%$.

${ }^{28}$ La proposición que estipula al mapuzugun como un instrumento importante para la transmisión de la historia propia gozó de un 96,8\% de aceptación. En el mismo sentido, aquella que propone al mapuzugun como instrumento para la continuidad de la costumbre mapuche tuvo un $79,5 \%$ de aceptación.

${ }^{29}$ Un 57,4\% de los entrevistados se manifestó de acuerdo con que el mapuzugun debería tener más utilidad, más presencia en los esfuerzos mapuches por surgir en la vida. 
y pesar por la interrupción de su transmisión en el seno de las familias mapuches (un $89,1 \%$ ). Esta toma de posición favorable a la lengua se prolonga hasta la disposición activa dirigida a actuar por ella. Este punto queda bien ratificado con el 97,9\% de aprobación respecto a la aseveración de que los propios mapuches deben tener una mayor preocupación por mantener el mapuzugun. Posición afirmativa que se sostiene, aunque con menor fuerza, con el 89,2\% de acuerdo en personalmente aprender mapuzugun, aumentar los conocimientos y habilidades, o mantener la destreza con la lengua cuando se la domina. El cambio es importante, sin embargo, cuando se pasa a la consideración de los caminos a transitar y los actores que deben concurrir para inducir cambios positivos en la dirección del sostenimiento y desarrollo de la lengua. Al igual que en el sur del país, se concibe que sean los mayores quienes preferentemente se impliquen en la enseñanza del mapuzugun (un 77,7\% de acuerdo) ${ }^{30}$. Al mismo tiempo, sin embargo, se apoya con mucha fuerza la proposición de que se requiere una competencia alta con la lengua para hablarla, lo que por el purismo implicado termina siendo un contrasentido y amenaza conformarse en un obstáculo.

Pasando ahora a las condiciones externas de reproducción de la lengua, fuera de los límites étnicos, se repetiría la tendencia a desplazar, a adoptar posiciones que se podrían quizá calificar como de extrañamiento y exterioridad, a la hora de convenir a quién le corresponde primordialmente y con qué medios impulsar la recuperación de la lengua. Las agencias públicas son crecientemente vistas como ese sujeto y las instituciones escolares el lugar en que ello debería producirse. Así, a la hora de pronunciarse acerca de si la continuidad del mapuzugun es una tarea del gobierno más que de los mapuches, un 52,0\% se manifestó de acuerdo y sólo un 31,0\% lo inverso. En complemento de lo anterior, un 94,6\% se manifestó de acuerdo en que la enseñanza del mapuzugun fuera obligatoria en los establecimientos escolares, y para los niños en general.

\subsection{Lengua, cultura y educación mapuche en la Región Metropolitana (2005)}

Se puede parcialmente complementar los resultados cuantitativos resumidos más arriba con antecedentes conseguidos en un estudio cualitativo reciente. Éste se basó en entrevistas individuales y colectivas referidas a lengua, cultura y educación en la Región Metropolitana (Gundermann, 2005) 31 y abordó cuatro comunidades

\footnotetext{
${ }^{30}$ Se entiende, dado que en contextos urbanos los mayores son los que principalmente conocen la lengua. Pero, al mismo tiempo, esos ancianos son pocos y el estado de compromiso de la lengua es tal que en modo alguno basta con esto.

${ }^{31}$ En lo relativo a la lengua mapuche y las actitudes asociadas se eligieron cuatro comunidades escolares metropolitanas donde existía una mayor presencia relativa de indígenas urbanos y en cada caso se realizaron entrevistas individuales a algunas personas (profesores, dirigentes de base, direc-
} 
escolares con alta presencia indígena (mapuche en su casi totalidad) ${ }^{32}$. Según la información reunida, la competencia lingüística mapuche urbana se concentra en las primeras generaciones de inmigrantes. Ellos son los que aprendieron, practican o practicaban la lengua. A veces la transmiten a sus hijos, pero lo más frecuente es lo contrario ${ }^{33}$. Asimismo, una proporción de emigrantes proviene desde zonas del centro sur de Chile donde la lengua mapuche se conoce y practica poco o ha prácticamente desaparecido ${ }^{34}$. El contingente de hablantes pasivos y activos urbano es retroalimentado por nuevos emigrantes provenientes desde zonas con mapuche hablantes, puesto que la movilidad hacia zonas urbanas no se ha detenido. Pero, en esos grupos de hablantes también los cambios se han pronunciado en favor del castellano. Una parte de los inmigrantes directos de antaño, algunos de los llegados más recientemente y a veces algunos de sus descendientes representan entonces el reservorio de hablantes disponible para cualquier acción en materia de

tivos y apoderados) y cuatro entrevistas colectivas, una por cada comunidad seleccionada. En los testimonios presentados hemos optado por mantener en el anonimato a las personas entrevistadas, reservando el apellido de ellas.

${ }^{32}$ Las comunidades escolares se distribuían dos en la Provincia Cordillera y dos en la Provincia Costa o Poniente. Con ellos se buscó cubrir todos o la mayoría de los tipos de realidades de comunidades escolares indígenas presentes en la Región Metropolitana. En el estudio de la experiencia y visión de la lengua indígena se abordarán cuatro grandes líneas temáticas: a) la percepción (visión y experiencia) de la Educación Intercultural Bilingüe (EIB) en el contexto metropolitano; b) la experiencia y visión de las lenguas indígenas en el contexto metropolitano; c) la disposición existente para la enseñanza de las lenguas indígenas; y d) la visión de la institucionalidad en relación con educación y pertinencia cultural.

${ }^{33}$ La disposición a la castellanización completa acompaña toda la experiencia migratoria mapuche del último medio siglo. Más aún, participa no sólo de la confrontación con la vida urbana y sus necesidades de comunicación, sino que arranca desde sus orígenes rurales. Existía en las zonas de emigración la muy extendida convicción de que para enfrentar el futuro los mapuches debían necesariamente adquirir las capacidades lingüísticas y de conocimiento necesarias para enfrentar nuevos desafíos de gran envergadura (crisis de sustentabilidad en la agricultura campesina, creciente integración de zonas indígenas a las regiones y el país, expansión del sistema escolar). Y esta certeza se confirmó y desarrolló cuando se debió responder a las exigencias de una condición de inmigrantes en una ciudad capital, con sus requerimientos de alfabetización, manejo del castellano, capacitación laboral, herramientas de comunicación y cognitivas para enfrentar un ambiente social a veces hostil y en cualquier caso no solidario con lo indígena. El siguiente relato es bastante elocuente: "En el caso de mi mamá, ella quiso perder... su identidad mapuche, la quiso perder porque ella decía de que su padre siempre fue muy 'achilenado', como se dice... No quería ser mapuche. Entonces decía que los mapuches no estudiaban, que prácticamente no le gustaban como eran. Entonces, el no quería que sus hijos fueran iguales, sino que quería que estudiaran, que se educaran y que perdieran el hablar mapuche, porque eso significaba como que eran ignorantes, una cosa así. O sea, el no valorizó de que era su cultura, era su lengua. Entonces quería solamente hablar en castellano. Entonces le fue diciendo a sus hijos de que no, que no hablaran ese idioma, que ellos tenian que hablar castellano, que tenian que educarse y que tenian que ser distintos" (Pilar).

${ }^{34}$ Como lo consigna el siguiente testimonio: "Yo soy mapuche. Tengo los apellidos A... Ll... [apellidos mapuches], pero yo me crié en el sur, en Valdivia. Pertenezco a la provincia de Valdivia. Pero yo allá..., mis papas nunca hablaron mapuche. Mi abuelito no más hablaba, pero cuando estaba curado, o cuando nos retaba, asi en garabatos. Entonces yo no tengo idea de nada casi [con] las palabras [en mapuzugun]" (Cecilia). 
Orgullo cultural y ambivalencia: Actitudes ante la lengua originaria en la sociedad mapuche... / H. Gundermann K.

política lingüística y fomento a través de la educación ${ }^{35}$.

Para las nuevas generaciones de mapuches urbanos la lengua originaria es ajena a su experiencia inmediata ${ }^{36}$. La han escuchado, conocen algún vocabulario, y a veces pueden desenvolverse con ella más allá de los saludos y frases de circunstancia que son comunes. Estas situaciones virtuosas son poco frecuentes ${ }^{37}$. Para jóvenes y adolescentes en particular, la lengua de sus abuelos y bisabuelos puede representar un anacronismo, un retorno del pasado no siempre bienvenido ${ }^{38}$. Se

${ }^{35}$ Según el estudio sociolingüístico basado en encuestas realizado en 2008, de un total de 2.707 personas mayores de 10 años acerca de las cuales se obtuvo información a partir de entrevista a hogares, un 7,9\% era bilingüe (de algún tipo) con aprendizaje del mapuzugun como primera lengua, un $11,8 \%$ era bilingüe (con una considerable variedad interna) con el castellano como primera lengua, y el restante 80,3\% monolingüe del castellano (Gundermann et al., 2009: 19). A través, ahora, de la aplicación de un test de competencia, se obtienen resultados todavía más modestos. Sorteando un integrante de cada uno de los 845 hogares visitados, de ellos 102 casos (12,2\%) demostraron algún nivel de competencia con la lengua. Ella se distribuía como sigue: competencia básica un 12,7\%, competencia media un 54,9\% (principalmente pasiva) y alta un 32,4\% (Idem: 40 ). Una distribución de este tipo es entendible solo a condición de asumir, como lo mostró el estudio, que existe una base de inmigrantes que aprendieron la lengua en las regiones de origen y que los que nacen en la Región Metropolitana obtienen un limitado y principalmente pasivo nivel de competencia.

${ }^{36} \mathrm{El}$ testimonio siguiente es aclarador al respecto: "mis papás... ellos son los dos nacidos y criados [en el sur de Chile], emigraron muy jóvenes y eran hablantes. Sin embargo, a nosotros jamás nos dijeron ni una palabra. Pero, yo entiendo [que lo hacían] como un afán de protección ante la discriminación del chileno... Mi mamá llegó analfabeta. Siempre decía, yo recuerdo de chica, que decía: ¡lo único que quiero es aprender a leer y escribir! Ella a los cuarenta años fue a la escuela y aprendió a leer y escribir, o sea adulta... Entonces van ocultando cosas, van ocultando elementos de su cultura, la lengua. Jamás nos enseñaron a nosotros, porque ella me decía siempre: nosotros queremos que ustedes hablen bien, porque de repente hay palabras que ellos no pronuncian bien en el castellano, el español. Entonces, ino!, ustedes tienen que hablar bien. Entonces, jamás nos transmitieron... Saben muchas cosas, pero las tienen ocultas, no quieren compartirlas [a sus hijos] por miedo. Yo creo que es eso. Sufrieron tanto, fueron tan ofendidos, tan discriminados, de una forma tan cruel que ellos se refugian y... ojalá pasar desapercibidos ante los demás" (María Isabel).

${ }^{37}$ Pero existen: "Yo creo que no hay mucho [de transmisión de la lengua]. Bueno, depende también de cada familia. En el caso de nosotros como familia nunca se perdió. Porque también yo naci acá, pero soy mapuche neto de mi generación. Mis hijos, mis sobrinos, toda la familia en general siempre se comparte todo lo que es el mapudungun. No lo hablamos de corrido tal vez, pero lo entendemos y nos manejamos cuando nos juntamos" (Flor).

${ }^{38}$ Posiblemente todos o una inmensa mayoría de los metropolitanos mantiene hoy una percepción de su vínculo con el pueblo mapuche, pero ello es muy variable en contenido intelectual, implicación emocional y compromiso existencial. Respecto de la lengua, un padre constata la inutilidad de sus esfuerzos: "Al mayor de todos le compré un libro, para que entendiera de hablar en mapuche... lo que es lo mapuche, lo que es el bosque, lo que es el multrün, lo que es el melqui, muday, todo eso, significados[s] de la palabra. En el libro todo eso salia... no estudió na poh, al final se fue pal sur... [Tengo] cinco hijos y una hija, yo les hablo en mapuche y a mi no me entienden, no entienden. El mayor entiende pero no sabe contestar. Son hijos mios, de sangre mapuche verdadero, de padre y madre, pero... no se interesa la juventud de ahora" (José). A veces, se puede aceptar para sí mismos, en condición de adultos, compartir y abrirse hacia las expresiones culturales mapuches urbanas, pero se presentan obstáculos para que los menores, hijos o parientes menores se inmiscuyan en la cultura: "Iban ellos, pero los niños no. Iban la gente adulta pero los hijos, los nietos no iban. En este caso, cuando hicimos el palín, que [es] una de las primeras actividades que hicimos aqui en la comunidad, fue toda la gente adulta pero poco niño... la gente no motiva a los niños" (Flor y Gloria). 
tiene entonces, una progresión de la competencia lingüística del tipo siguiente: los llegados mantienen la máxima competencia relativa; luego un salto muy fuerte se presenta en la primera generación urbana y un estado extremo de desconocimiento se da en el caso de la tercera o cuarta. La mayoría de los indígenas metropolitanos es urbano por nacimiento y por opciones de vida. La apropiación de la lengua mapuche puede hoy significar mucho para algunos, pero para otros poco más que una mirada al pasado sin consecuencias personales importantes en el presente y futuro.

Lo anterior podría extrañar si se recuerda que en las últimas dos décadas se vive un ascenso vertiginoso en la valoración de la cultura y la lengua nativas por parte de los indígenas del país, situación de la cual no escapan los mapuches urbanos $^{39}$. Es efectivo que ello ha venido ocurriendo y bien lo atestigua la mayoría de las personas entrevistadas en el estudio. Pero, lo anterior se lleva a efecto en un campo de fuerzas sociales en que es notorio, primero, un efecto de diferenciación personal y familiar en que se adopta una amplia gama de decisiones (desde la completa identificación y activismo étnico, hasta el completo desinterés por cualquier implicación cultural o incluso ignorancia de todo ello). Segundo, uno de diferenciación generacional en que la participación de adultos y ancianos inmigrantes es mayor que la de niños, jóvenes y adultos propiamente metropolitanos, con intereses y compromisos más diversificados. Y tercero, un efecto de disociación entre valoración de lengua y cultura -ahora con atributos positivos para muchos-, y compromiso de conocimiento y desempeño con ellas.

Esa distancia entre subjetividad (que discursivamente valora lo propio) y prácticas culturales y lingüísticas sería general, aunque con variantes y diferencias, a lo rural y lo urbano y a los inmigrantes y los nacidos en la Región Metropolitana. Los requerimientos funcionales de comunicación en una sociedad integrada profusamente, la incapacidad actual de las lenguas indígenas de insertarse en la realidad social contemporánea, los resabios de valoraciones negativas sobre lo indígena, así como la extendida percepción de cultura del pasado para la costumbre mapuche, las presiones genéricamente denominadas como "discriminación", todo ello nos es

${ }^{39}$ Un caso de autoadscripción cultural individual: "Me llamó la atención mi apellido, alguien me dio el significado de mi apellido y empecé con el bichito. El bichito de que, bueno iy la cultura? [De que] yo soy mapuche, y empecé a aprender que yo era mapuche, empecé a aprender mi cultura, empecé a aprender algo de la lengua" (Paulina). La persona que entrega el testimonio resalta la conciencia del apellido como un factor que la conduce a la pregunta y la reflexión sobre la cultura. De allí, según se puede colegir, se pasa a la identificación con una pertenencia mapuche y junto con ello, a un interés activo por un aprendizaje, parcial al menos, de nociones y prácticas culturales, incluidas en ellas a las lingüísticas. Los propios entrevistado(a)s que entregaron los testimonios presentados provienen de un segmento de personas con una viva conciencia de pertenencia al pueblo mapuche, con orgullo cultural, con una visión de diferencias y fronteras étnicas muy marcada, así como con una gran sensibilidad sobre la omisión, negación, prejuicios, discriminación, ofensas y violencia hacia lo indígena y mapuche. Por cierto, otras tomas de posición y disposiciones podrán encontrarse entre quienes no experimentan ni promueven convicciones, posiciones y actividad cultural mapuche. 
Orgullo cultural y ambivalencia: Actitudes ante la lengua originaria en la sociedad mapuche... / H. Gundermann K.

propuesto como explicación por las personas entrevistadas individual o colectivamente en el estudio que se reseña.

\subsection{Transmisión, enseñanza y continuidad lingüística en la percepción mapuche del sur de Chile (2007)}

Las razones y justificaciones aducidas por las personas mapuches acerca de por qué transmitir la lengua vernácula o no hacerlo nos ayudan a identificar ideas, percepciones y disposiciones sobre ella; esto es, elementos de ideologías lingüísticas. La gran mayoría de las respuestas a la pregunta abierta de encuesta: “¿Por qué se les habla (o hablaba) mapuzugun a los niños de la casa? (habló o enseñó en caso de no haber niños en el hogar)" ${ }^{40}$ se concentra en estipulaciones de lealtad y compromiso cultural con el pueblo mapuche y lingüístico con su lengua (un $87,9 \%$ de las respuestas en que se registran acciones de transmisión de la lengua, 912 casos ${ }^{41}$. En otros pocos casos la justificación radica en el compromiso familiar o personal para la transmisión de lengua y cultura (un 3,2\% de los casos). Se fundamenta que la lengua era hablada por los parientes mayores (padres, abuelos) y resulta importante, por respeto y amor a ellos, o por compromiso de ellos mismos, que su saber y sus conocimientos lingüísticos sigan presentes en la familia ${ }^{42}$. Tales declaraciones pueden también entenderse como formas de adhesión y lealtad lingüística y cultural, expresada a través de una acción motivada en la posesión de ello por integrantes de la familia. Una variante de respuesta (que reunió el 2,1\% del total) no insistió en fundamentos valóricos y tomas de posición cultural sino que en el estado favorable de conocimiento y práctica de la lengua en el hogar ${ }^{43}$. Como sabemos, estas situaciones familiares internas favorables están disminuyendo.

Otra vertiente de respuesta (con un 6,8\% de los casos) tuvo una orientación distinta a la mera descripción de un estado de cosas comunicativo estimulante o su

${ }^{40}$ Incluida en el estudio basado en encuestas: "Perfil sociolingüístico de comunidades mapuche de la VIII, IX y X Región” de 2008, resumido más arriba.

${ }^{41}$ Denotan lo anterior expresiones recogidas tales como: "porque soy mapuche, para no perder mi lengua"; "que no se pierdan nuestras raíces"; "que no se pierda la costumbre"; "para no perder la identidad"; "que no se pierda el idioma de nosotros"; [para] "que ellos [los hijos] sepan que somos mapuches"; "para que lleven el conocimiento mapuche y no se pierda en el tiempo"; "porque es nuestra lengua y no queremos que se pierda", etc.

42 Por ejemplo: "Porque nuestro idioma nunca debe perderse, esto me enseñó mi padre y madre y lo mismo tengo que enseñarles [a ellos sus hijos]; "para que él [nieto] diga que su abuela le transmitió algo". Estas acciones toman a veces modulaciones más personales e incluso lúdicas: "Para que no digan que yo fui egoista con mis hijos"; "para que aprendan lo que yo se"; "porque a ellos les gusta escuchar mapudungun"; [porque] "me gusta hablar el idioma con los niños".

43 Por ejemplo: "Estamos acostumbrados [a hablar mapuzugun], así como nos criaron yo los he criado"; "porque siempre hablábamos mapudungun y ellos asi aprendieron"; "por costumbre, porque para nosotros [en este hogar] es más fácil hablar mapudungun". 
justificación con arreglo a valores de lealtad y compromiso lingüístico y cultural. Ahora se argumenta que el aprendizaje de la lengua es un medio o sirve a fines que no son sólo los relativos a la lealtad lingüística o cultural. Identificamos tres fórmulas: a) el mapuzugun como necesidad interna de comunicación: "porque estamos en una comunidad indigena y para comunicarnos con los demás"; [para que] "puedan comunicarse con las personas ancianas que hablan mapudungún", también expresado a veces como un recursos cultural de defensa, o la necesidad de manejar la lengua frente a un eventual empleo malicioso por otros mapuches de la localidad: "que no sean engañados"; "que no la hagan tonta". b) Algo relativamente novedoso y que no deja de causar alguna perplejidad si se tiene en cuenta la historia de rechazo, es la lengua como demanda externa. En particular desde algunos establecimientos escolares se pide una participación activa de los hogares en la enseñanza de la lengua nativa: "porque los profesores le piden eso"; "dar información que piden en la escuela"; "para fortalecer lo que le enseñan en la escuela". Y, c) el valor del bilingüismo y el idioma como una forma ilustrada de capital cultural, como una ventana, apoyada ahora en una renovada legitimidad: "porque [con la lengua] se desarrollan más"; "para que sepan dos idiomas".

\subsection{La interrupción de la transmisión y sus justificaciones en el sur de Chile (2007)}

De interés para precisar mejor las percepciones mapuches acerca de la lengua son las respuestas a la pregunta, hecha en el mismo estudio que se acaba de mencionar, acerca de por qué no se les habla (o hablaba) mapuzugun a los niños de la casa (o habló o enseñó en caso de no haber niños en el hogar). En poco más de dos tercios de las respuestas válidas (un 72,4\%, de un total de 1.080) se menciona falta de capacidad de los progenitores (y/o abuelos o mayores del hogar y la familia) para hablar, enseñar y en definitiva transmitir la lengua. Fueron y siguen siendo hogares básicamente monolingües del castellano o con conocimientos muy limitados de mapuzugun ${ }^{44}$. Es la variante más numerosa de respuestas por la no enseñanza y transmisión.

En un cierto número de casos que alcanza un 5,3\% se indicó que no se poseían capacidades con la lengua, pero que además no se quiso, no se tuvo interés o no se tomó la iniciativa para su enseñanza y aprendizaje $\mathrm{e}^{45}$, o bien se aducen factores del

\footnotetext{
${ }^{44}$ Estas situaciones son verbalizadas con expresiones del tipo: "no tengo tanto conocimiento de la lengua mapuche"; "no sé hablar mapudungun"; "porque yo nunca lo aprendi a hablar"; "porque no sabemos hablar ese idioma, no comprendo cómo se pronuncia"; "porque nadie me ha enseñado a hablar a mî", o "mi mamá sabe pero los niños nunca van a su casa y yo no sé hablar mapuzungun", etc.

${ }^{45}$ Lo que queda ilustrado por declaraciones como las siguientes: "Porque no me gusta y además no pude aprender"; "porque yo sabia hablar mapudungun muy poco y me daba vergüenza hablarlo";
} 
contexto de residencia, trabajo y vida familiar que refuerzan la ausencia de competencias, el más importante de los cuales sería la carencia de ambientes sociales con bilingüismo ${ }^{46}$. También se trae a colación la discriminación sufrida ${ }^{47}$. Uno de los agentes de discriminación sería la escuela ${ }^{48}$.

Otra línea de respuestas proviene de hogares en que se reconoce la posesión de conocimientos lingüísticos en grados diversos, pero que a pesar de eso no se transmite o transmitía la lengua a los menores. Corresponde a situaciones en que a pesar de esas capacidades, ellas no se concretan en acciones con consecuencias de aprendizaje, representan un 22,3\% de los casos. Manifiestan una considerable heterogeneidad interna. Una categoría es aquella en que se dan restricciones comunicativas en el seno de los hogares ${ }^{49}$. Otros se refieren a la falta de iniciativa, ausencia de interés o insuficiente motivación ${ }^{50}$. Una variante de lo anterior es el desinterés consciente, la falta de voluntad sustentada en una decisión razonada, a diferencia de los casos anteriores en que no se destaca un ejercicio reflexivo ${ }^{51}$. A veces se señala la incapacidad de enfrentar las dificultades que son propias a la enseñanza de una segunda lengua, el mapuzugun, cuando la lengua general es el castellano, trasladando así la responsabilidad de su no enseñanza y continuidad a estos problemas ${ }^{52}$. Se obtienen también expresiones de rechazo explícito por parte de los progenitores o de miembros mayores de una familia ${ }^{53}$. Con mayor frecuen-

"no sé mucho el mapuzungun, nunca me enseñaron, porque a ellos ya no les interesaba"; "nunca nos ha interesado la lengua huilliche, tampoco aprenderlo"; "porque yo no sé nada sobre mi lengua, a mi no me enseñaron cuando yo era chica, mi marido tampoco sabe nada, porque él no es mapuche", etc.

${ }^{46}$ Lo que se testifica con expresiones como: "En este lugar no se practica mucho la lengua"; "mis padres no hablaban huilliche, ni tampoco en el sector se habla este idioma"; "no le hablé a mis hijosporque no se usa el mapuzugun en esta zona"; "viviamos en Santiago y porque para entender [lo urbano] hay que hablar castellano"; "porque no es necesario hablar mapudungun en el pueblo".

${ }^{47}$ Por ejemplo: "No nos enseñaron porque mis padres fueron discriminados por hablar huilliche y de ahi se fueron olvidando de sus raices huilliches".

${ }^{48}$ Así se indica: "Se olvidó [la lengua] porque en la escuela le quitaron hablar el mapudungun"; "no manejo el idioma y [antes] en la escuela se prohibió el mapudungun".

${ }^{49}$ Por ejemplo, a partir del hecho de que "ellos [los hijos] estudian y no conversan con uno"; "porque su esposa es 'chilena' [no indígena] y como [la lengua] no se habla frecuentemente, es difícil que aprendan"; "se acostumbró con el castellano, mi hijo es mezclado [mapuche - 'chileno'] y menos le hablaba", etc.

${ }^{50}$ Esta falta de impulso queda bien expresada por las siguientes respuestas: "Nunca me motivé para hablarles"; no tuve tiempo para enseñarles el mapudungún"; "no hay personas interesadas [en el hogar] para hablar el mapudungun"; "me acostumbré a hablar [sólo] castellano con mi marido"; "porque se ha perdido la costumbre de hablar"; "si, nos habló, pero nunca aprendimos".

${ }^{51}$ Por ejemplo: "No lo quiero hablar", "creo que no vale la pena aprenderlo, a uno como persona no le sirve para dialogar con personas no mapuches", "a nadie ahora le interesa hablar en mapudungun". Ello puede tomar la forma de una devaluación abierta: "Porque no sirve para ninguna cosa; porque no era una cosa interesante", o bien constituir una opción definida: "Para que no le cueste hablar castellano"; "para que aprendieran a hablar perfecto el castellano".

${ }_{52}$ Por ejemplo: "No me entiende nada de lo que hablo"; "no me van a entender"; "no se habla, porque nadie nos entiende"; "si les hablo, pero mis nietos no entienden y no lo toman en cuenta".

${ }^{53}$ Por ejemplo: "Él [jefe de hogar] nunca ha querido que se hable mapudungun en la casa"; "a mi 
cia este rechazo se hace presente entre integrantes de las nuevas generaciones, entre los jóvenes de los hogares. Menudean así respuestas que hablan de una oposición activa por parte de quienes están en posición de aprendizaje del mapuzugun como segunda lengua ${ }^{54}$.

Hogares con conocimientos de la lengua vernácula suelen también aducir factores externos o de contexto para justificar la no transmisión, eventualmente combinados con razones internas a los grupos familiares. La escuela pública y la enseñanza formal, el desempeño allí, sus presiones y represiones aparecen bien destacados ${ }^{55}$. También se entregan respuestas menos inculpatorias, pero que muestran bien el ambiente, los problemas y las prioridades que debieron y deben asumir respecto de la lengua los hogares mapuches del tipo descrito ${ }^{56}$. Las opciones son claras: favorecer la educación que se imparte en castellano y la coexistencia con otros sectores de población, porque esa lengua prevalece sin discusión en la comunidad lingüística local a la que se pertenece. Además, para un porcentaje mayoritario y creciente de los mapuches del sur de Chile su experiencia de vida es en la actualidad exclusiva o principalmente urbana. Y ello tiene sus consecuencias para el uso de la lengua y también para su conservación y transmisión ${ }^{57}$. Muchos advierten que con el cambio de residencia, de una rural a una urbana, se dejó atrás la lengua, justificando su abandono por la fuerza de los hechos: "Llegamos a la ciudad y no se habló más". No se habla y, por tanto, no se enseña "porque [ya] nunca vivimos en el campo", asociando directamente lengua indígena con ruralidad. Estas decisiones pueden sustentarse en motivaciones poderosas $^{58}$. El impacto de las experiencias agraviantes vividas en el campo y la ciudad de destino debido al uso de la lengua deja huellas y consecuencias en la falta de incentivo para transmitirla a los hijos: "porque nosotros sufrimos mucho por no saber hablar la lengua castellana”.

esposo no le gusta"; "ellos [los padres] no quieren y no les gusta hablar [la lengua]".

${ }^{54}$ Los padres o adultos recibirían reacciones de los menores del tipo: "Ellos se ríen"; "no comprenden [lo que se les habla] y se enojan"; "ellos [los hijos] se avergüenzan"; "no sacamos nada con hablar porque no nos toman en cuenta los niños"; "les he tratado de enseñar a mis hijos y nietos, pero se rien de mí, asi es que no les enseñé más"; "trato de enseñarles, pero ellos se enojan conmigo y me retan, les da vergüenza a mis hijos y me critican porque yo soy mapuche".

${ }^{55}$ Por ejemplo: "[sabe] muy poco porque los niños los castigaban en la escuela, los profesores les prohibian hablar en mapuche"; "porque en el colegio era muy delicado [problemático] hablar chezugun a los hijos"; "los niños no quieren porque en la escuela se burlaban".

56 "Se les hablaba, pero en el colegio se les olvidó, pero si entienden"; "porque ella estaba en la escuela internada y no va casi nunca a la casa"; "porque en el colegio no hablan mapudungun"; "en el colegio hablan puro castellano, en el pueblo también".

57 "En el pueblo no se habla mapudungun" y, por lo tanto, no se justifica su transmisión: "porque no y además no sirve de mucho, y nadie ya está usando el mapuzugun".

${ }^{58}$ La lengua y su manifestación expone al prejuicio y las vejaciones: "no tocamos [más] el tema de la lengua; porque si lo hablo soy discriminada por los vecinos, me tratan de "india". 
Orgullo cultural y ambivalencia: Actitudes ante la lengua originaria en la sociedad mapuche... / H. Gundermann K.

\section{IDEOLOGÍAS LINGÜÍSTICAS, LENGUA SUBORDINADA Y ETNOGÉNESIS}

Según la información presentada, tanto en el centro sur del país como en la Región Metropolitana se da a la lengua y la cultura mapuches un alto valor, potencial expresivo y dignidad, equivalentes al castellano y la cultura nacional. Gozan así de una notable autoridad y legitimidad ${ }^{59}$. La fuerza de la afirmación lingüística tiene sustento histórico, a la vez que se apoya en una renovada adhesión y orgullo cultural. Este es uno de los aspectos más resaltantes de las ideologías lingüísticas presentes en la cultura mapuche contemporánea. Sin embargo, se trata ante todo de una legitimidad interna, que no alcanza más allá de la esfera de vida propiamente mapuche en la medida que se concibe, preponderantemente, como una institución cultural de y para los mapuches, aplicable a las necesidades comunicativas y expresivas internas. En efecto, las dudas se hacen presentes a la hora de trasladar su presencia y vigencia más allá de los ámbitos sociales y dominios de comunicación intraétnicos. Ello se aprecia bien cuando se da una relevante funcionalidad interna a la lengua, pero una mucho más reducida cuando se plantea su funcionalidad externa. Pero aun respecto de esas funciones internas el correlato práctico o el ejercicio sistemático con ella se ha debilitado, cuestión que se hace especialmente visible para los propios mapuches en regiones como las de Los Lagos y Los Ríos o en la Región Metropolitana, donde el monolingüismo castellano es la constante.

La percepción de la pérdida de vitalidad de la lengua y su fragilidad se ha extendido. Su permanencia y la necesidad de revitalización es algo que no suscita dudas. Varias de las justificaciones de por qué transmitir la lengua cuando se la conoce insisten en un "para que no se pierda". Las declaraciones sostienen una alta disposición a actuar en su favor. En este mismo plano se aprueba la necesidad de una mayor implicación de cada mapuche en favor de su lengua. Pero valorar e implicarse intelectual y emocionalmente con la lengua no resulta sinónimo de un compromiso o voluntad efectivos con su cultivo; ello no gatilla automáticamente cambios en las prácticas lingüísticas. Al mismo tiempo, pensando en los agentes internos, se concibe un rol dinamizador claramente más allá de sus posibilidades para los mayores y ancianos. Surgen también voces que defienden un purismo lingüístico no necesario ni prioritario en las circunstancias actuales. Y cuando se pasa a los externos, se cifran esperanzas más allá de toda realidad en lo que pueda hacer hoy la escuela pública y otras agencias estatales de apoyo. Tocante a esto último, en el seno de la sociedad mapuche empieza a pensarse el aprendizaje del mapuzu-

59 Se debe recordar que la información obtenida en estos estudios y en otros en el sur de Chile y en la Región Metropolitana está influida por el ambiente de validación y activismo cultural en curso. 
gun como un tipo de práctica escolar a cargo de establecimientos educacionales que atienden niños indígenas. Empieza a razonarse en la escuela como relevo a la familia y las redes y grupos sociales inmediatos. En especial allí donde no se tiene conocimientos de la lengua en el hogar, o aquellos son mínimos, y lo mismo sucede con las localidades en que se vive ${ }^{60}$.

La argumentación acerca del orgullo cultural y la lealtad lingüística en el plano discursivo es posible de conectar con esa percepción de vulnerabilidad y precariedad de la lengua, aunque de una manera problemática. La prevalencia de expresiones del tipo "para no perder mi lengua" y otras similares (cf. nota 42) para justificar la enseñanza y transmisión del mapuzugun es sintomática de una conciencia de amenaza y precariedad, pero, a la vez, posiciona la lengua en necesidades internas y en el pasado. De esta manera, queda la imagen de que esas necesidades internas no son primordial y prioritariamente de comunicación (mantener un flujo de comunicación generalizado y vital), sino de contención del retroceso lingüístico y, al mismo tiempo, de simbolización como colectividad. Por así decirlo, se debe transmitir y usar la lengua tanto o más "para no perder las raíces" o "para no perder la identidad", que para mantenerla vigente. Y el recurso a "las raices", la identidad, la costumbre o el patrimonio forman una percepción conectada al pasado. Sólo muy marginalmente se concibe el aprendizaje y dominio de la lengua con un sentido presente y futuro; por ejemplo, sostenido en el valor del bilingüismo, la importancia de la ilustración, o los alcances más modestos de sintonizar con demandas escolares de los hijos. Se trata, entonces, de actitudes defensiva, pero con alcances y eficacia limitados. Se tiene conciencia, a veces, o al menos se intuye, en otras, que ninguna lengua de un pueblo originario puede sostenerse en el tiempo para rememorar el pasado y significar la etnicidad, sin que al mismo tiempo posea funciones lingüísticas relevantes con consecuencias para el presente y futuro de las personas mapuches.

Las dificultades con la transmisión de la lengua vernácula trae a colación un aspecto de la enseñanza-aprendizaje de una lengua tradicional que no siempre se repara en su cabal importancia. El aprendizaje del mapuzugun hoy se lleva efecto en condición de segunda lengua; es la realidad de aprendizaje prevalente, cuando llega a realizarse. Sin embargo, se la sigue tratando como si no fuera una lengua socialmente dominada, sujeta a una condición de minorización ${ }^{61}$ y en franco re-

${ }^{60}$ Todas materias del más alto interés intelectual y práctico que en este trabajo sólo se puede tocar someramente en razón de mantener unidad temática y por razones de espacio.

${ }^{61}$ El mapuzugún es la lengua de una minoría socialmente subordinada, sujeta a procesos de dominación económicos, políticos y cultural-idiomáticos de larga data, como bien lo señala la investigación sociohistórica. La noción de minorización expresa en el plano lingüístico ese estado de dominación. Nos parece oportuno citar la siguiente definición: "Une langue est considérée comme minorée, lorsqu'elle se caractérise par tout ou partie des critères sociolinguistiques suivants. 1. L'absence de status officiel: la langue minorée n'est pas officielle, co-officielle ou nationale. 2. L'absence d'usages institutionnalisés: la langue minorée n'est pas autorisée pour la rédaction de 
Orgullo cultural y ambivalencia: Actitudes ante la lengua originaria en la sociedad mapuche... / H. Gundermann K.

troceso, respecto de la cual no es suficiente, como antaño, el dinamismo del ambiente comunicativo hogareño y familiar para asegurar una adecuada transmisión y el reclutamiento de nuevos hablantes que se suman al ejercicio comunicativo en la lengua vernácula ${ }^{62}$. Dicho de otra manera, se sigue tratando la transmisión de la lengua como algo que puede dejarse al curso de los acontecimientos de la vida diaria mapuche. Y ello ya no es posible hoy sin consecuencias negativas como las que se están produciendo.

Lo anterior llevó y lleva a que la percepción interna (de los propios mapuches) y externa (de la sociedad a la que están más íntimamente integrados cada día) acerca del bajo prestigio relativo de la lengua mapuche sea algo extendido, antiguo y asumido como un dato de la realidad. Tal estado de cosas fue aceptado con resignación y muchas veces ni siquiera hecho consciente o verbalizado como un real problema. La minorización tiene así consecuencias en las percepciones y actitudes mapuches ante su lengua y el bilingüismo, llegando a considerar como relativo al orden de las cosas que el uso de ella tenga existencia y valor sólo en ámbitos de relaciones sociales intraétnicas. El mundo de la comunicación verbal y escrita les parecía y todavía parece segmentado en una lengua propia apreciada y valorada en la comunicación entre mapuches, en esferas de interacción social étnicas. Y en una lengua general que resulta indispensable aprender y manejar, oralmente y por

textes officiels, administratifs. 3. Elle n'est pas médium ou matière d'enseignement. 4. Sa diffusion est essentiellement orale. La production écrite est inexistante ou marginale (quelle que soit par ailleurs sa function emblématique). 5. Elle ne béneficie pas d'un accès aux médias audio-visuels. 6. L'acquisition de la langue minorée se fait essentiellmente dans le cadre familial, et pas à l'école. 7. Sa rentabilité sociale est restreinte, sa connaissance restant sans profit pour le locuteur en terme de mobilité sociale, de promotion professionelle. 8. La langue minorée n'est pas en distribution concurrente avec d'autres langues, mais en distribution complémentaire: la langue dominante assure la fonctions véhiculaire quand la langue dominée a des fonctions vernaculaires et emblématiques (identitaires). 9. Les rapports fonctionnels de la langue minorée avec une langue dominante sont stables dans la longue durée. 10. La langue minorée ne connaît pas de processus de normalisation/ standarisation. Ses différentes variétés ne font pas l'objet d'un mouvement d'unification; il ne cée pas une variété élaborée de langue, ou elle ne se diffuse pas: la langue minorée nést pas soumise à des processus de grammatisation (réduction de la variation par le recours à l'écrit et la conformation des productions écrites à un standard, objet de description métalinguistique) et il n’y est donc pas associé d'outils de régulation des usages (dictionnaires, codification orthographique...)" (Kasbarian, 1997: 186-187).

${ }^{62}$ En Latinoamérica diglosia suele emplearse para cubrir un dominio de fenómenos semejante al que describe el de minorización. En la acepción que se ha extendido en nuestro medio describe una "situación en la que en una sociedad concreta, una o varias lenguas se ven subordinadas a otra que goza de mayor prestigio social en lo que se refiere a las funciones que cumple. La lengua dominante y de prestigio es utilizada en todos los contextos y ámbitos y constituye un idioma de uso formal; la lengua oprimida y dominada es relegada al plano informal y doméstico, fuera del cual no tiene funciones instrumentales" (López, 1988: 92; cit. por Chiodi y Loncón, 1999: 44). No es posible por razones de espacio entrar en una discusión de detalle relativa a las posibles ventajas de una noción sobre otra. En tanto se haga claridad de en qué sentido se está usando uno u otro término y su empleo arroje consecuencias de conocimiento, pueden justificarse instrumentalmente como recursos conceptuales válidos. 
escrito, en niveles que les den suficiencia para desenvolverse en la sociedad mayor.

Los mapuches perciben hasta cierto punto esa dominación estructural y, en cualquier caso, la palpan y experimentan en su vida cotidiana y trayectorias vitales. Advierten, por ejemplo, que en diversos dominios la lengua propia no sólo se encuentra frente a la posición dominante con que los actores en interacción imponen el castellano, sino que su lengua carece de recursos lingüísticos (prácticas de escritura extendidas, recursos lexicales ampliados) para desenvolverse allí (por ejemplo, en el ámbito de la tecnología; o el lenguaje de la administración pública). Toman cuenta también del aumento del monolingüismo castellano y del carácter sustractivo del bilingüismo existente. Pero respecto de ello, con la salvedad de algunas personas y familias, no se ha extendido suficientemente una acción consciente y activa para contrarrestar la pérdida de vitalidad ("relajamiento" la llaman Chiodi y Loncón, 1995: 27) ${ }^{63}$. Se valora la lengua, pero por lo general se deja que las cosas ocurran.

La dominación, la minorización y la percepción de desprestigio que recae genéricamente sobre la lengua no significa, entonces, que históricamente-digamos, durante el último siglo- el mapuzugun carezca de prestigio interno. Es durante este periodo que se asiste a la progresiva exclusión (por omisión de cualquier consideración oficial respecto de reconocer y promover la lengua), minorización (establecimiento de una posición subordinada) y retroceso (en su vitalidad), aunque con persistencia de un prestigio manifiesto, pero limitado exclusivamente a la esfera social mapuche. Esto hace del prestigio, en el sentido de respeto, reputación o posición social, un atributo relativo a los ámbitos sociales de que se trate. Si se refieren a las relaciones sociales internas a la lengua se le reconoce prestigio; éste cede ese sitial en favor del castellano si se trata de las relaciones externas y sus desafíos (trabajo, educación, comercio, ámbitos urbanos, movilidad social). Sobre este particular no hay dos opiniones (Fernández y Ramos, 1983: 44; Croese, 1983: 27; Fernández y Hernández, 1984: 44; Chiodi y Loncón, 1995: 29-30; Chiodi y Loncón , 1999: 37-38; Gianelli, 2007: 101; Catrileo, 2010: 43).

Ahora bien, este prestigio permanece hasta hoy, con dos cambios visibles que se busca diferenciar y resaltar. Primero, la vitalidad interna de la lengua se encuentra notoriamente amenazada (incremento exponencial del monolingüismo castellano; pérdida de niveles de competencia; interrupción de la transmisión intergeneracional, etc.), cuestión respecto de la cual tampoco existen dos opiniones (Gianelli, 2007; Zúñiga, 2007; Gundermann et al., 2008; Gundermann et al., 2009; quizá con algo más de optimismo Catrileo, 2010; lo reconocen también los estudios urbanos de Wittig, 2009 y Lagos, 2012). El aprecio que resulta de ser el vehículo

${ }^{63}$ La noción de relajamiento supone un estado previo de activa y en buena medida consciente implicación en la reproducción de la lengua a través de su uso y enseñanza. En verdad, sólo en el presente y en casos acotados se actúa de esa manera sobre la lengua. Su transmisión se ha dejado históricamente al efecto de aprendizaje resultante del uso espontáneo y cotidiano de ella. 
de comunicación con la familia, los parientes y la comunidad, o para la intimidad y los afectos, tiene menos posibilidades de expresarse a medida que la lengua retrocede allí donde mejor permanece (las áreas rurales de vida mapuche en la Araucanía), que los límites entre lo interno (comunidades rurales) y lo externo (pueblos, ciudades, áreas rurales intensamente comunicadas) se hacen cada vez más difusos y los nexos más dinámicos, o que cambia la condición de residencia y las formas de vida cotidiana (de rural a urbana). Por lo que amenaza con transformarse en un prestigio nominal. El segundo depende de un proceso mucho más reciente y con apoyo en el reconocimiento étnico alcanzado, que otorga a la lengua una posición gravitante en la formulación de una representación o ideología sobre qué es lo cultural mapuche. Esto es, la reelaboración de la representación del mapuzugun como un poderoso símbolo étnico, en la misma medida -aunque por razones diferentes- que la lengua retrocede en vitalidad. Y todo ello envuelto por un proceso más general de etnogénesis (Eriksen, 2010); o sea, de conformación de actores colectivos, prácticas políticas, un conjunto de derechos y acción simbólica que dan forma a la ecuación cultura - etnia (o pueblo originario) que se ha llevado a efecto durante los últimos 25 años, aproximadamente ${ }^{64}$. Las dos tendencias resumidas hacen más complejo sostener, por la discordancia resultante, una correspondencia mecánica entre prestigio interno ascendente y usos lingüísticos efectivos declinantes. En definitiva, se hace más difícil mantener congruencia en la lealtad lingüística, que tiende así a hacerse cada vez más discursiva.

\section{CONCLUSIONES}

En los parágrafos siguientes se entrega un resumen de lo que, referente a las ideas y actitudes mapuches ante su lengua, se extrajo de los estudios presentados, la literatura consultada y lo que hemos formulado del análisis realizado con base en ese material y la bibliografía acerca del tema. Se considera que esta ideología lingüística se ha constituido en una situación de dominación social, minorización y bilingüismo de larga duración que evoluciona y que también es influida por

${ }^{64}$ Lo cultural nunca había tenido una importancia política y jurídica equivalente a la que adquirió en los últimos tiempos. Podemos entender este fenómeno como el resultado de demandas sostenidas por líderes y organizaciones en una estructura de oportunidades políticas favorable (la del retorno a la democracia en Chile). Sus resultados, la Ley Indígena $\mathrm{N}^{\circ} 19.253$ y sus reglamentos, la ratificación del Convenio 169 de la OIT y una extendida concepción de la pertenencia colectiva indígena como etnia o pueblo originario. De allí que convenga, destacando esta novedad, llamar a este proceso como de etnogénesis (al respecto, confróntese Eriksen, 2010: 155-157). Entiéndase bien, con esto no se quiere en modo alguno insinuar que previamente no existían organizaciones mapuches, demandas, legislación, prácticas culturales, lengua propia o fronteras sociales de alteridad. Lo que decimos es que se trata de otra historia, con la que la actual guarda continuidad en algunos aspectos (restitución de tierras), pero también cambios fundamentales en otros (demandas de autonomía colectiva o centralidad política acordada a lo cultural). 
cambios ideológicos y políticos más recientes.

Caracteriza la formación de las modernas ideas y actitudes acerca del mapuzugun el contrapunto entre un sostenido prestigio interno y la percepción de baja valoración que se le otorga externamente como "dialecto" o "idioma de indios". Ese prestigio o valor positivo interno se objetivó en funciones y ámbitos de uso exclusivos a la vida social en los hogares, grupos de parentesco y comunidades mapuches, preferentemente aquellos rurales. Ese contraste tiene al castellano como lengua oficial exclusiva en posición dominante que, a medida que se impone e incorpora en la sociedad mapuche y en tanto la lengua vernácula se mantiene recluida a servir funciones tradicionales, progresivamente crea una realidad de minorización lingüística. Formando parte de todo ello está la constatación de la carencia de funciones del mapuzugun fuera de los espacios sociales mapuches y la percepción de la absoluta necesidad del castellano a medida que la educación formal obligatoria se va imponiendo y que las esferas de actividad mapuche se expanden (a través de las emigraciones y de la participación en los mercados de trabajo regionales). Un componente del mismo conjunto de disposiciones es entonces la asunción de la educación formal escolarizada como el instrumento a través del cual se obtiene un castellano apropiado a las necesidades comunicativas del presente y el futuro de las personas. Con la expansión del bilingüismo se establece la percepción de que el castellano podía emplearse en los ámbitos internos, aunque con algunas limitaciones dadas por normas más o menos implícitas de uso exclusivo -o al menos preferente y deseable- del mapuzugun para dominios como el religioso y ritual. Ello se acompaña de una posición por lo general pasiva -con las salvedades indicadas- frente a la expansión del castellano en los dominios comunicativos en que éste iba imponiéndose, como pasiva resulta la actitud ante la lengua propia en el sentido que se reproduciría por sí misma en el seno de las familias y las comunidades mapuches.

Se aprecian cambios en el presente que cabe ponderar. De una parte, el prestigio de la lengua se ha reforzado en la sociedad mapuche ya que la mayoría de sus miembros asume una posición ideológica de la lengua y la cultura mapuche como equivalentes con el castellano y la cultura nacional. A esto se agrega la idea normativa de que el mapuzugun acompañe a los mapuches estén éstos donde estén, a diferencia del pasado en que se pensaba la lengua como una dimensión cultural rural y atinente sólo a lo tradicional. Se observa también una decidida aspiración a que la lengua se dinamice (recupere vitalidad interna); es decir, una toma de posición discursivamente positiva y activa frente a la lengua. En relación con esto se detecta algún interés, no carente de ambigüedad y controversia, de que la lengua se extienda más allá de los límites de lo mapuche.

La otra cara de los nuevos aires de valoración cultural y lingüística es la per- 
cepción de carencia de funciones para el mapuzugun más allá de estrechos límites de comunicación interna. Según los contextos de que se trate, se advierten las dificultades para contar con ella, como la necesidad en Santiago de recurrir a especialistas rituales no sólo por su competencia con la religiosidad para los oficios correspondientes, sino que también por sus capacidades con la lengua tradicional. También se denota la limitada extensión y ausencia de recepción fuera de lo mapuche, como no sea para la simbolización de identidad/alteridad a través de performances lingüísticos, señaléticas y algunos materiales escritos. Toman significado, asimismo, que persiste una relativamente baja consideración en la sociedad nacional por su lengua y cultura, salvo quizá en un sector todavía poco numeroso de la población.

Persiste la noción de la lengua como una institución cultural propia que se reproduciría por sí misma en el seno de los grupos mapuches. Y, por lo tanto, se sigue en los hechos manteniendo una posición básicamente pasiva, un sustraerse a la hora de actuar para sí mismos en el aprendizaje y expansión de las competencias lingüísticas. Notables excepciones están representadas por la acción de algunas familias y personas, además de talleres de lengua, iniciativas de inmersión lingüística y el compromiso de docentes fluentes en su lengua, pero cuya cobertura es todavía muy reducida. A lo anterior acompaña una posición usualmente acrítica y contemplativa frente a la expansión del castellano sobre los dominios que antaño dominaba el mapuzugun. Destaca, asimismo, una muy primaria definición de los medios, recursos y agentes, en buena medida vistos como externos, que deberían actuar en la revitalización lingüística.

¿Y qué cambió, entonces? Se ha establecido hoy un nuevo orgullo cultural que promueve la revaloración y reposicionamiento de lengua y cultura. Representa en esta medida una ideología lingüística positiva reforzada. Y en relación con ello surgen esfuerzos autogestados, realizados por personas y grupos mapuches, para aprender y ganar competencia cultural y lingüística (como lo destacan Lagos, 2012, y Wittig, 2009). El entorno ofrece también algunos cambios como la puesta en funciones de un Programa de Educación Intercultural Bilingüe (EIB) y un ambiente en el país de algo mayor tolerancia a la diferencia cultural y lingüística. Pero esto tiene lugar mientras las tendencias de disminución en la vitalidad lingüística no han cambiado de curso y la situación estructural de dominación lingüística sigue siendo tan real como cuando se estableció en el siglo pasado. Se enfrenta entonces la paradoja de, por una parte, un incremento del prestigio, legitimidad, peso simbólico y valor social otorgado a la lengua y, por otra, usos, funciones y competencias lingüísticas declinantes. Ello conduce a que, en contra de lo esperable, la congruencia en la lealtad lingüística no ha aumentado, ha disminuido y, por lo tanto, ésta tiende a hacerse más discursiva. 


\section{REFERENCIAS}

Ancapi, Ana. (2006). ¿De la invisibilización al reconocimiento? Estrategias y ámbitos de reconstrucción de la cultura y la identidad mapuche de dos agentes culturales indígenas en la ciudad de Concepción. Tesis de Maestría en Educación Intercultural Bilingüe, ProeibAndes, Universidad Mayor, Cochabamba, Bolivia, Ms. 192 págs.

Carrasco, Hugo. (2002). El discurso público mapuche: noción, tipos discursivos e hibridez. Estudios Filológicos, 37, 185-197.

Catrileo, María. (2010). La lengua mapuche en el siglo XXI. Valdivia: Universidad Austral de Chile.

Chiodi, Francesco y Elisa Loncón. (1995). Por una nueva politica del lenguaje. Temas y estrategias del desarrollo lingüistico del mapudungun. Temuco: Universidad de la Frontera, Edit. Pehuén.

Chiodi, Francesco y Elisa Loncón. (1999). Crear nuevas palabras. Innovación y expansión de los recursos lexicales del Mapuzugun. Temuco, Chile: UFRO CONADI.

Croese, Robert. (1983). Algunos resultados de un trabajo de campo sobre las actitudes de los mapuches frente a su lengua materna. RLA. Revista de Lingüistica Teórica y Aplicada, 21, 23-33.

Eriksen, Thomas Hylland. (2010). Ethnicity and nationalism. Anthropological perspectives. Londres - New York: Pluto Press.

Fasold, Ralph. (1996). La sociolingüistica de la sociedad. Madrid: Visor Libros.

Fernández, Arturo y Ramos, Nelly. (1983). Situación sociolingüística de una familia mapuche. Proyecciones para abordar el problema de la enseñanza del castellano. RLA. Revista de Lingüistica Teórica y Aplicada, 21, 35-44.

Fernández, Isabel y Arturo Hernández. (1984). Estudio exploratorio de actitudes en una situación de bilingüismo. El caso mapuche. RLA. Revista de Lingüistica Teórica y Aplicada, 22, 35-51.

Foerster, Rolf y Montecino, Sonia. (1988). Organizaciones, líderes y contiendas mapuches (1900-1970). Santiago: Ediciones CEM.

Gianelli, Luciano. (2007). Dominio y redes de empleo del mapuzugun en el marco rural mapuche. Signos Lingüísticos, 5, 97-118.

Gundermann, Hans. (2005). Lengua, cultura y educación intercultural en la Región Metropolitana. Estudio cualitativo en colegios de comunas con alta población indígena. Santiago: MINEDUC - UTEM (inédito).

Gundermann, Hans. (2013). Procesos étnicos y cultura en los pueblos indígenas de Chile. Alpha, Revista de Artes, Letras y Filosofia, 36, 93-108.

Gundermann, Hans, Caniguan, Jaqueline, Clavería, A. y Faúndez, C. (2008). 
Orgullo cultural y ambivalencia: Actitudes ante la lengua originaria en la sociedad mapuche... / H. Gundermann K.

Perfil sociolingüístico de comunidades mapuche de la VIII, IX y X Región. Santiago de Chile: CONADI - UTEM.

Gundermann, Hans, Godoy, Luis, Caniguan, J., Ticona, E., Castillo, E., Clavería, A. y Faúndez, C. (2009). Perfil sociolingüístico de lenguas mapuche y aymara en la Región Metropolitana. Santiago de Chile: CONADI - UTEM.

Kasbarian, Jean-Michael. (1997). Langue minorée et langue minoritaire. En Marie-Louise Moreau (ccord.), Sociolinguistique. Les concepts de base (pp. 185188). Liége: Mardaga.

Lagos, Cristián. (2012). El mapudungún en Santiago de Chile: Vitalidad y representaciones sociales en los mapuches urbanos. RLA. Revista de Lingüistica Teórica y Aplicada, 50, 161-184.

Lavanchy, Javier. (2003). El pueblo mapuche y la globalización. Documento. Seminario de Postgrado. Escuela de Postgrado de la facultad de Filosofía, Universidad de Chile, Santiago.

Lipschutz, Alejandro. 1968. El movimiento indigenista y la reestructuración cultural americana. En Perfil de Indoamérica de nuestro tiempo. Antología 19371962 (pp. 86-103). Santiago: Editorial Andrés Bello.

Olate, Aldo y Marisol Henríquez. (2011). Actitudes lingüísticas de profesores mapuche de Educación Básica: vigencia y enseñanza del mapudungun en el contexto educativo. Literatura y Lingüistica, 22, 103-116.

Sesiones de la Cámara de Diputados. (1927). Sesión 86 Extraordinaria de la Cámara de Diputados, 2 de febrero de 1927, págs. 3345-3382. Versión digital disponible en http://historiapolitica.bcn.cl/historia_legislativa. Consulta: $14 / 12 / 2012$.

Téllez, Eduardo. (2001). El levantamiento del Alto Biobío y el Soviet y la República Araucana de 1934. Anales de la Universidad de Chile, 13, 151-175.

Wittig, Fernando. (2009). Desplazamiento y vigencia del mapudungún en Chile: Un análisis desde el discurso reflexivo de los hablantes urbanos. RLA. Revista de Lingüistica Teórica y Aplicada, 47, 135-155.

Woolard, Kathryn. (1992). Language ideologies: issues and approaches. Pragmatics, 2 (3), 235-249.

Woolard, Kathryn. (1998). Introduction: Language Ideology as a field of inquiry. En Schieffelin, Bambi, Woolard, Kathryn y Kroskrity, Paul (eds.), Language ideologies. Practice and theory (pp. 3-47). New York, Oxford: Oxford University Press.

Zapata, Claudia. (2005). Identidad y sujeto en la escritura de los intelectuales mapuches de Chile (1993-2003). Claroscuro, 4, 51-76.

Zapata, Claudia. (2006). Identidad, nación y territorio en la escritura de los intelectuales mapuches. Revista Mexicana de Sociología, 68 (3), 467-509. 
Zapata, Claudia. (2008). Los intelectuales indígenas y el pensamiento anticolonialista. Discursos/prácticas, 2, 113-140.

Zúñiga, Fernando. (2007). Mapudunguwelaymi am? ¿acaso ya no hablas mapudungun? Acerca del estado actual de la lengua mapuche. Estudios Públicos, 105, 9-24. 